\title{
Revisiting the Diabetes-Heart Failure Connection
}

\author{
Markus Wallner ${ }^{1,2,3} \cdot$ Deborah M. Eaton ${ }^{2} \cdot$ Dirk von Lewinski $^{1} \cdot$ Harald Sourij ${ }^{3,4}$
}

Published online: 20 October 2018

(C) The Author(s) 2018

\begin{abstract}
Purpose of the Review To summarize current clinical data investigating the link between diabetes and heart failure pathophysiology, the association of glucose control with heart failure, and the impact of current antihyperglycemic drugs on heart failure. Recent Findings Although heart failure is one of the most prevalent outcomes occurring in real life and cardiovascular outcome trials, insufficient attention was given to this condition in diabetes research over the last decades. With both beneficial and detrimental findings for heart failure hospitalization in the health authority-mandated outcome trials for new antihyperglycemic agents, research on heart failure and its interplay with diabetes mellitus gained momentum.

Summary Diabetes mellitus and heart failure are both prevalent and intertwined conditions. While currently available heart failure therapies have a similar degree of effectiveness in patients with and without diabetes, the choice of glucose-lowering agents can substantially affect heart failure-related outcome.
\end{abstract}

Keywords Diabetes · Antihyperglycemic drug · SGLT-2 inhibitors · Incretin-based therapy · Heart failure · Pathogenesis · Treatment

\section{Introduction and Epidemiology}

In 2014, 422 million people were affected by diabetes mellitus, and the number of patients diagnosed is estimated

This article is part of the Topical Collection on Macrovascular Complications in Diabetes

Harald Sourij

ha.sourij@medunigraz.at

Markus Wallner

Markus.wallner@medunigraz.at

Deborah M. Eaton

tug65856@temple.edu

Dirk von Lewinski

dirk.von-lewinski@medunigraz.at

1 Division of Cardiology, Department of Internal Medicine, Medical University of Graz, Graz, Austria

2 Cardiovascular Research Center, Lewis Katz School of Medicine, Temple University, Philadelphia, PA, USA

3 Center for Biomarker Research in Medicine, CBmed, Graz, Austria

4 Division of Endocrinology and Diabetology, Department of Internal Medicine, Medical University of Graz, Auenbruggerplatz 15, 8036 Graz, Austria to increase to almost 700 million by 2040 [1,2]. Diabetes is a global epidemic, associated with a two- to fourfold risk increase for cardiovascular diseases [3] and a two- to fivefold risk increase for developing heart failure (HF) compared to age- and risk factor-matched patients without diabetes [4]. This supports the idea of a specific intrinsic mechanism driving the distinct pathophysiological mechanism for cardiac remodeling in this population. On the one hand, advances in the management of acute coronary syndrome [5] and improvements in HF treatment have led to a significant reduction in both morbidity and mortality [6-8], but on the other hand, both improvements are thought to be responsible for an increase in prevalence of HF. Thus, HF has become one of the most prevalent cardiovascular (CV) diseases in the Western world, and its mortality exceeds most types of cancers. It is worth noting that the prevalence of HF is even higher in patients with diabetes $[9,10]$. Conversely, the prevalence of diabetes is high in patients hospitalized for HF with reduced ejection fraction [11].

\section{Complex Interplay of HF and Diabetes}

Glucose intolerance and HF are clinically and pathophysiologically interdependent, such that the worsening of one condition is frequently accompanied by worsening of 
the other [12]. Metabolic disorders in patients with diabetes often worsen in parallel with the progression of HF and improve after its treatment $[13,14]$. Notably, it seems that HF is one of the most common complications in clinical outcome trials, especially in patients with diabetes, despite excluding patients with $\mathrm{HF}$ at baseline [15]. Furthermore, patients with diabetes and HF have a very poor prognosis, which is associated with high health care costs $[16,17]$. There is up to a tenfold increase in mortality in patients with diabetes and HF compared to patients with diabetes without HF, which is associated with a 5-year survival rate of only $12.5 \%$ [18]. These findings underline the importance of the interplay between HF and diabetes. It is important to note that HF therapy is of similar effectiveness in patients with and without diabetes and is standardized in international guidelines [19-21]. However, the management of diabetes in HF patients seems to be less clear. While observational studies reported a significant association between lower glucose levels and less macrovascular disease, data from randomized controlled trials are generally not supportive of intensive glycemic control [22-24]. For example, in the observational analysis of the United Kingdom Prospective Diabetes Study (UKPDS) [25], an association between cardiovascular complications and glycemic control was shown, demonstrating that for every $1 \%$ decrease in circulating glycosylated hemoglobin $\left(\mathrm{HbA}_{\mathrm{lc}}\right)$, there was a $14 \%$ reduction in myocardial infarction (MI) events and a $16 \%$ risk reduction of HF [25].

Another study reported that during long-term follow-up of patients without $\mathrm{CV}$ disease, troponin $\mathrm{T}$, a marker of cardiac injury, rose in parallel with $\mathrm{HbA}_{\mathrm{cc}}$. This increase in troponin $\mathrm{T}$ was associated with future clinical outcomes (HF, death) [26]. In a recent cohort study that included over 270,000 patients with type 2 diabetes mellitus (T2DM), who were registered in the Swedish National Diabetes Register, diabetes was associated with an increased risk for hospitalization for heart failure, even if all cardiovascular risk factors were well controlled [27]. In this analysis, $\mathrm{HbA1} \mathrm{c}$ was shown as a prominent factor associated with heart failure risk [27]. Large randomized controlled trials, such as VADT [22], ADVANCE [24], and ACCORD [23], which assessed the effects of intensive versus less intensive glycemic control, did not report a reduced risk of HF. The optimal level of glycemic control in patients with HF is still uncertain, with some data suggesting that tight glycemic control increases the risk of hypoglycemia, which was associated with poorer outcomes [28]. Since the Federal Drug Administration (FDA) [29] and European Medicine Agency (EMA) began mandating cardiovascular outcome trials for newly developed antihyperglycemic drugs, many cardiovascular outcome trials have been conducted. The composite primary endpoint usually selected is major adverse cardiac events (MACE), which includes CV death, non-fatal MI, and non-fatal stroke. Many of the recently conducted outcome trials have included adjudicated hospitalization for
$\mathrm{HF}$ as a secondary endpoint. In this review, we summarize the results of the main clinical outcome trials in regard to HF $[30,31]$.

\section{Pathophysiology}

Numerous factors play a role in the development of diabetes, many of which also contribute to the progression of heart failure. The underlying mechanisms involved in both diseases influence the structure, function, and metabolism of the heart. Diabetic cardiomyopathy is defined as a clinical condition of ventricular dysfunction in the absence of coronary atherosclerosis and hypertension in patients with diabetes [32]. In the early stages, diabetic cardiomyopathy is usually asymptomatic. A decrease in LV compliance, reflected by an impaired early diastolic filling and prolonged isovolumetric relaxation, is one of the earliest manifestations of diabetic cardiomyopathy [33]. Furthermore, an increase in interstitial and perivascular fibrosis has been found in the diabetic heart, which is different from the fibrosis observed following MI and with coronary artery disease or hypertension [34-36]. There is also an increase in collagen cross-linking [37]. Other structural changes include cardiac hypertrophy, which may be increased by hyperinsulinemia due to insulin resistance [38, 39]. Hyperglycemia leads to an increase in the production of mitochondrial reactive oxygen species (ROS), causing a state of oxidative stress when increased beyond the anti-oxidative capacity of the cell [40]. Oxidative stress plays a major role in downstream diabetic complications and may also be involved in gene activation and remodeling of the myocardium due to cell death mediated by ROS [39]. The diabetic heart is also characterized by an upregulation of proinflammatory cytokines, including vascular cell adhesion molecule 1 ; interleukins $1 \beta, 6$, and 7 ; monocyte chemotactic protein 1 ; and tumor necrosis factor- $\alpha$ [41, 42]. Endothelial cells, cardiomyocytes, fibroblasts, and smooth muscle cells are all impacted by this upregulation of proinflammatory cytokines and increase in ROS/oxidative stress [41]. There is also an accumulation of advanced glycation end products (AGE) in a diabetic state [43]. Dyslipidemia has been described in type 2 diabetes and is characterized by an increase in triglycerides, low HDL-C, and an increase in small-dense LDL. An increase in triglycerides causes elevated HDL catabolism, which causes the decrease in HDL-C and a shift in LDL towards the more atherogenic small-dense LDL phenotype [44]. An increase in the glycation of apolipoproteins and oxidation of LDL has also been reported [45]. Abnormalities in adipokine secretion, which includes adiponectin, leptin, apelin, and adipsin, occur in both diabetes mellitus and heart failure and may exert a multitude of downstream pathophysiological effects [46]. In vitro experiments have found insulin to have a direct positive inotropic effect via $\mathrm{Ca}^{2+}$-dependent and $\mathrm{Ca}^{2+}$-independent mechanisms using isolated human ventricular myocardium 
[47]. The sarcoplasmic reticulum load is increased, which increases systolic $\mathrm{Ca}^{2+}$ transients and the sensitivity of myofilaments $[34,47]$. Other calcium abnormalities include decreased activity of sarco/endoplasmic reticulum $\mathrm{Ca}^{2+}$-ATPase $2 \mathrm{a}$ (SERCA2a) [48]. Insulin also mediates a change in the energy substrate of the heart by increasing the supply of pyruvate [49, 50]. In the diabetic heart, there is a shift in metabolic substrates, with a decrease in glucose availability [51] and an increase in fatty acid oxidation to meet energetic demands [39]. In early stages of heart failure, there is a metabolic substrate shift from fatty acids to glucose oxidation, but in later more advanced stages, insulin resistance may develop and a decrease in glucose utilization may occur $[39,52]$. Studies have found insulin resistance to be an independent predictor of heart failure patients worsening prognosis [53]. Diabetic metabolic abnormalities follow the progression of heart failure, so a decline in the cardiovascular system or an improvement following treatment will be reflected metabolically [12]. However, the effects observed on heart muscle cannot be separated from those on fluid regulation. For example, insulin has been suggested to cause sodium retention in diabetes [54]. Delineating the effects of antihyperglycemic drugs on heart failure is complex and requires large-scale clinical trials.

\section{Insulin}

$\mathrm{HF}$ is associated with significant changes in myocardial insulin signaling, which influences myocardial structure and function. Hence, insulin resistance in HF may contribute to adverse left ventricular remodeling and mitochondrial dysfunction [55]. In experimental studies using insulin, proinflammatory [56], vasoconstrictive [57], and anti-natriuretic [58] effects were reported, which are all likely to be undesirable in patients with HF. Furthermore, the sodium retaining effect of insulin is preserved even when other tissues are in a state of insulin resistance [59]. In some retrospective analyses of clinical trials and observational studies, insulin treatment has been consistently associated with poorer outcomes compared to non-insulin treatment strategies [60-62]. A clear limitation of observational studies is the inability to distinguish between "causality" (insulin is harmful) or a confounding effect when associations are observed, since insulin-treated patients who usually have more advanced stages of $\mathrm{CV}$ and renal diseases are older and have a longer history of diabetes than those treated with oral antihyperglycemic agents.

In the ORIGIN trial, which enrolled 12,537 patients with $\mathrm{CV}$ risk factors and impaired fasting glucose, glucose tolerance, or T2DM, subjects were randomly assigned to receive insulin or standard care. The composite co-primary endpoint (death from $\mathrm{CV}$ causes, non-fatal MI, non-fatal stroke, CV revascularization, or hospitalization for $\mathrm{HF}$ ) did not differ between the insulin and standard care group (HR, 1.04; 95\% CI, 0.97 to $1.11 ; p=0.27)$. Hospitalization rates for $\mathrm{HF}$ were also similar between groups (HR, 0.90; 95\% CI, 0.77-1.05) [63]. It is important to note that the ORIGIN trial also included patients with a very short history of T2DM or no diabetes diagnosis. A small randomized clinical trial of only 40 patients with T2DM and established HF compared the effects of optimized diabetes treatment with insulin to no optimization for 4 months. There was no difference in myocardial contractile reserve, oxygen consumption, and exercise capacity between the groups [64]. Taken together, there is only sufficient data for insulin glargine demonstrating a neutral effect with regard to heart failure in subjects with short diabetic history, but otherwise, the data available regarding insulin treatment in HF patients is inconclusive and requires more extensive clinical trials.

\section{Sulfonylureas}

Sulfonylureas achieve glycemic control via an increase in insulin release by closing the ATP sensitive potassium channel on the beta cell. This mechanism of action can cause both weight gain and hypoglycemia, which can exacerbate HF.

Safety data for sulfonylureas in patients with established HF is mainly available from observational studies with varying results. Data from the Saskatchewan Health databases found sulfonylureas to increase both the mortality and hospitalization rate for HF compared to metformin (metformin vs. sulfonylureas; HR, 0.83; 95\% CI, 0.70-0.99) [65]. Consistent with these findings, another retrospective analysis reported an increased mortality (metformin vs. sulfonylureas; HR, 0.54; 95\% CI, 0.46-0.64) and risk for HF (metformin vs. sulfonylureas; HR, 0.76; 95\% CI, 0.64-0.91) with sulfonylureas compared to metformin [66]. A Danish registry study found similar findings [67]. Conversely, Masoudi et al. found no evidence that sulfonylureas increased mortality compared to other glucose-lowering agents (HR, 0.99; 95\% CI, 0.91-1.08) in a retrospective cohort study with 16,417 patients with T2DM and $\mathrm{HF}[68]$.

In UKPDS, newly diagnosed patients with T2DM (3867) without cardiovascular disease were randomly assigned to receive either sulfonylurea (chlorpropamide, glibenclamide, or glipizide), insulin, or conventional dietary-based treatment. HF events were comparable between the sulfonylureas $(3 \%)$ and the conventionally treated group $(3.3 \%)$ (HR, $0.91 ; 95 \%$ CI, 0.54-1.52) [69]. The sulfonylurea gliclazide was used in the ADVANCE trial for the intensive treatment group, and no significant difference in heart failure was shown between this treatment group compared to the standard control group. Since this trial was designed to compare intensive glucose control versus standard control, the effects of gliclazide and intensive glucose lowering are difficult to distinguish.

Given the lack of properly designed randomized controlled clinical trials and conflicting results from observational studies, the safety of sulfonylureas remains uncertain. The risk of hypoglycemia and weight gain, as well as the availability of 
other classes of antihyperglycemic drugs with proven cardiovascular safety or benefits, has reduced the use of sulfonylureas in recent years.

\section{Thiazolidinediones (glitazones)}

Thiazolidinediones (TZDs) enhance insulin sensitivity and endothelial function while also improving the lipid profile, which may slow down the progression of atherosclerosis. The PROactive trial found that pioglitazone did not reduce the primary endpoint of all-cause mortality, non-fatal MI, non-fatal stroke, acute coronary syndrome, and revascularization (HR, 0.90; 95\% CI, 0.80-1.02); while the secondary composite endpoint, including all-cause mortality, non-fatal MI, and non-fatal stroke were reduced (HR, 0.84; 95\% CI, 0.720.98) [70]. However, TZDs cause edema and weight gain, and several clinical trials reported an increased risk of HF with TZDs. In the PROactive trial, pioglitazone significantly increased the hospitalization rate for HF compared to placebo (6\% in the pioglitazone group vs. $4 \%$ in the placebo group; $p=0.007$ ), without an increase in HF-related mortality [70]. Similar findings were reported in the DREAM trial, where rosiglitazone was administered to patients with impaired fasting glucose or impaired glucose tolerance without CV disease. The TOSCA.IT randomized 3028 patients with diabetes and inadequate glycemic control with metformin monotherapy to either add-on pioglitazone or a sulfonylurea. The trial was terminated early based on a futility analysis. The primary composite endpoint of all-cause death, non-fatal MI, and stroke, or urgent coronary intervention, did not differ between treatment groups (HR, 0.96; 95\% CI, 0.74-1.26) [71]. Rosiglitazone was found to significantly increase the incidence of HF compared to the placebo group (rosiglitazone $0.5 \%$ vs. placebo $0.1 \%$; HR, 7.03; 95\% CI, 1.60-30.9) [72]. The RECORD trial was a multicenter, open-label trial, in which 4447 patients with T2DM on metformin or sulfonylurea monotherapy were randomly assigned to either add-on rosiglitazone or a combination of metformin and sulfonylurea (active control group). Treatment with rosiglitazone was associated with a doubled risk of HF hospitalization or HF-related death (61 vs. 29 cases; HR, 2.10; 95\% CI, 1.35-3.27) [73]. Only two small randomized trials have assessed the effects of TZDs on left ventricle (LV) ejection fraction (EF) in T2DM with HF. Although there was no adverse effect on left ventricular function, treatment with TZDs was associated with an increase in BNP as a predictor for poor CV outcome [74, 75]. In 2007, the FDA gave TZDs a black-box warning for use in acute or symptomatic chronic HF patients.

\section{Metformin}

Metformin is currently considered the primary therapeutic agent for glycemic control in T2DM based on low cost, tolerability, and the results of the UKPDS trial, which suggested improved CV outcomes [31]. However, the UKPDS trial reported very few HF events, which did not differ between metformin and conventional dietary treatment [69]. Furthermore, the results from the long-term follow-up of UKPDS did not report HF [76]. There is even less evidence regarding the effects of metformin in established HF. One randomized trial included 62 insulin-resistant $\mathrm{HF}$ patients treated with either metformin or placebo for 4 months. Metformin did not improve exercise capacity as assessed by peak oxygen uptake $\left(\mathrm{VO}_{2}\right)$ [77]. As with sulfonylureas, data about the safety of metformin as a diabetes treatment in conjunction with established HF is mainly derived from observational studies. It seems that metformin use in diabetic HF patients is associated with lower mortality and morbidity compared to other antihyperglycemic agents [67, 68, 78-80]. It is worth noting that previous concerns regarding metformin causing lactic acidosis are no longer justified [81, 82] and the FDA removed heart failure as a contraindication for metformin 2006 from the label. Although metformin may be associated with better outcomes, the clear limitations of observational studies must be considered. Therefore, randomized clinical trials are required to assess whether or not metformin improves outcome in diabetic HF patients.

\section{DPP-4 Inhibitors}

Plasma levels of dipeptidyl peptidase-4 (DPP-4) have been correlated with both human cardiac dysfunction and animal models of heart failure [83], highlighting the potential direct link between CV health and DPP family. Many cells and tissues express DPP-4 and also have exopeptidase activity against GLP-1, chemokines, and peptide hormones. DPP-4 is involved in glucose metabolism and regulation of vascular function, cell homing, and survival [84]. Other than the heart, DPP-4 inhibitors impact the vasculature, liver, immune system, kidneys, hematopoietic system, and neuroendocrine system via hormones per second messengers such as substance $\mathrm{P}$, brain natriuretic peptide (BNP), release of nitric oxide, and intracellular calcium concentrations [85]. Using DPP-4 inhibitors as a therapy in different models of heart failure resulted in improvements in the severity of HF, survival, and remodeling of the ventricle [86-90]. DPP-4 inhibitor clinical outcome trials produced mixed results. Large clinical outcome trials for sitagliptin, alogliptin, and saxagliptin have been published thus far. They all reported a neutral effect on the composite primary outcome, which included non-fatal MI, non-fatal stroke, and CV mortality (plus hospitalization for unstable angina in TECOS) with hazard ratios close to 1.00 . In the SAVOR-TIMI trial, which investigated saxagliptin, there was a significant increase $(27 \%)$ in HF hospitalizations (3.5\% for saxagliptin vs. $2.8 \%$ for placebo). The EXAMINE trial also showed a numerical yet not statistically significant 
increase in HF hospitalizations in the group that received alogliptin $(3.1 \%)$ vs. the placebo group (2.9\%). No increase in mortality was observed in either trial. In the TECOS trial, no difference in HF hospitalizations was observed between the sitagliptin vs. placebo group [91-93]. CARMELINA and CAROLINA, which are both investigating linagliptin, are in progress and the outcome data is expected in the near future. Currently, results for hospitalization for heart failure in the DPP-4 inhibitor trials are homogenous, highlighting potential differences between DPP-4 inhibitors within the same drug class. The interaction between DPP-4 inhibitors, the cardiovascular system, and more specifically cardiomyocytes has been previously established, but the direct link or mechanism connecting DPP-4 inhibitors to its effects on cardiac contractility and general function is still not fully understood. A recently published paper reported adverse off-target effects of saxagliptin on cardiac function by increasing diastolic calcium content [94]. Further mechanistic studies are necessary to develop a better understanding of the cardiovascular implications of DPP-4 inhibitors.

\section{SGLT-2 Inhibitors}

Sodium/glucose cotransporter 2 (SGLT-2) inhibitors are an exciting new advancement in the fields of cardiology and diabetes. The EMPA-REG-OUTCOME trial [95•] reported significantly improved CV outcomes, including all-cause mortality, in patients who had received treatment with one specific anti-diabetic drug. This was the first trial to report positive $\mathrm{CV}$ outcomes since the European Medicines Agency (EMA) and Federal Drug Administration (FDA) [29] began requiring cardiovascular outcome trials for all new antihyperglycemic drugs. The EMPA-REG-OUTCOME trial was a randomized, double-blind, placebo-controlled trial with 7020 patients with T2DM and established cardiovascular disease. They received once-daily empagliflozin treatment $(10 \mathrm{mg}$ or $25 \mathrm{mg}$ ) or placebo treatment. There was a significant reduction (HR, 0.86; 95\% CI, 0.74-0.99) of the combined primary endpoint encompassing CV death, non-fatal MI, and non-fatal stroke in T empagliflozin (pooled analysis)-treated patients during a mean follow-up of 3.1 years. These results were impacted by a decrease in CV death (HR, 0.62; 95\% CI, 0.49-0.77; $p<0.001)$. Another impressive result was a $35 \%$ relative reduction in the rate of HF hospitalizations in empagliflozintreated patients $(p<0.002)$. CANVAS and CANVAS-R [96], which are grouped together as the CANVAS program [97•], focused on canagliflozin, another SGLT-2 inhibitor. This study included 10,142 T2DM patients with a high CV risk and focused on CV safety and efficiency. Some of the results from this study were in line with the remarkable outcomes of the EMPA-REG-OUTCOME trial, while others differed. Canagliflozin significantly reduced the rate of primary outcome events, which encompasses CV death, non-fatal MI, and stroke by $14 \%$. It also reduced HF hospitalization by $33 \%$. Despite these positive results, canagliflozin did not significantly reduce $\mathrm{CV}$ or all-cause mortality. Cardiovascular outcome trials for dapagliflozin are currently in progress. The CVD-REAL (Comparative Effectiveness of Cardiovascular Outcomes in New Users of SGLT-2 Inhibitors) study, which was not a randomized controlled trial, extended the findings from both the EMPA-REGOUTCOME trial and the CANVAS program, but this needs to be confirmed in DECLARE-TIMI 58 (NCT01730534).

The mechanism of action for how SGLT-2 inhibitors improve cardiovascular outcomes has not yet been fully described, but there are many hypotheses. Very limited data is available offering mechanistic insight, which makes this an interesting new area of investigation. Empagliflozin has been found to improve diastolic dysfunction in mouse models of diabetes, potentially through anti-fibrotic effects and increased SERCA activity $[98,99]$. SGLT-2 inhibitors may also modulate energy metabolism of the myocardium, which may explain the positive CV effects [100]. Diabetic myocardium cannot oxidize fatty acids and metabolize glucose the same way a healthy heart can. SGLT-2 inhibitors may cause an increase in ketone bodies independent of diabetes, which allows for a shift in metabolic substrate utilization to fatty acids, having a beneficial impact on oxygen consumption and the work efficiency of the myocardium [100-102]. This is still an understudied area and raises many questions regarding the role of SGLT-2 inhibitors in cardiac metabolism and mechanisms of actions related to CV effects [103]. Another potential mechanism of action is that SGLT-2 inhibitors have a direct effect on the myocardium, even though there is an overall absence of cardiac SGLT-2 expression. Renal and cardiac isoforms of the sodium hydrogen exchanger (NHE) are upregulated in heart failure and diabetes, which suggests it may play a role in the relationship between the two $[12,104]$. Diastolic myocardial function is positively impacted by changes in intramyocardial $\mathrm{Na}^{+}$and $\mathrm{Ca}^{2+}$ fluxes and inhibition of $\mathrm{NHE}$ via SGLT-2 inhibitors [104]. Natriuresis and glucosuria have a systemic effect on hemodynamics by lowering plasma volume and blood pressure, which causes a decrease in pre-/and afterload [105, 106]. Importantly, the effects on blood pressure occurred without compensatory sympathetic activation and increase in heart rate. Additionally, a reduction in pulse pressure and arterial stiffness has been reported with SGLT-2 inhibition [107]. Another important finding is an increase in hematocrit during SGLT-2 inhibitor treatment, which is most likely mediated by the diuretic effect and an enhancement in erythropoiesis and is not associated with an increased risk for cerebral infarction. Under diabetic conditions, tubulointerstitial hypoxia induces impairments in erythropoietin production and this tubulointerstitial injury may be attenuated with SGLT-2 inhibition [108]. SGLT-2 inhibitors seem to impact the CV system independent of glucose control, 
which highlights their potential as a treatment option for nondiabetic HF patients [109]. The positive CV effects observed in the clinical trials speak for themselves, but determining what the mechanism of action is and if these drugs could have a beneficial impact in patients without diabetes who have a high CVD risk is very important [3]. The next group of SGLT2 inhibitor clinical trials includes multiple phase III outcome trials in non-diabetic HF patients, with both preserved ejection fraction (HFpEF) and reduced ejection fraction (HFrEF). These trials may offer further insight into the already impressive and exciting effects of SGLT-2 inhibitors (see Table 1).

\section{GLP-1 Receptor Agonists}

Glucagon-like peptide-1 (GLP-1) is an incretin peptide hormone primarily synthesized by intestinal L cells [110], which is released into the circulation in response to eating, leading to glucose-dependent insulin release and suppression of glucagon. The primary active isoform is GLP-1(7-36) $\mathrm{NH}_{2}$, which has a half-life of $2 \mathrm{~min}$. This active isoform is rapidly degraded by DPP-4 to GLP-1(9-36) $\mathrm{NH}_{2}$ [111], which is a GLP-1 receptor antagonist [112]. GLP-1 receptor activation also inhibits gastric and small bowel motility, reduces appetite, and ultimately leads to weight loss [113]. The GLP-1 drug class was shown to improve endothelial dysfunction, reduce infarct size post-ST segment-elevation MI, and improve cardiac output in mechanistic studies [114-117]. The beneficial effects of GLP-1 receptor agonists are thought to be the result of their direct action on the myocardium, more specifically in cardiomyocytes of the ventricle, as this is where most of these effects were reported. There have been conflicting results regarding the expression of GLP-1 receptor in cardiac tissue. Recent studies in mice and rats revealed that the GLP-1 receptor is exclusively localized in atrial cardiomyocytes [118-120].GLP-1 receptor expression in human right and left ventricular myocardium was documented by Wallner et al.; however, the expression was significantly lower compared to right atrial tissue [121]. This difference in expression may be an inherent caveat of translating basic science using animal models to humans because of the species-based differences between the two.

The first cardiovascular outcome trial for GLP-1 receptor agonists was the ELIXA trial, which studied lixisenatide. ELIXA enrolled T2DM patients who had previously suffered an acute coronary event within 180 days of screening. No significant difference was observed between the treatment and placebo group in terms of HF hospitalization or primary composite endpoint, which included cardiovascular death, MI, and stroke [122]. The SUSTAIN-6 trial tested the effect of semaglutide in T2DM patients with chronic heart failure, cardiovascular disease, chronic kidney disease, or subjects at an age $\geq 60$ years with at least one cardiovascular risk factor. There was a significant reduction in the risk for the primary endpoint, which was defined as the first occurrence of nonfatal MI, non-fatal stroke, or cardiovascular disease (HR, 0.74; 95\% CI, 0.85-0.95). These positive effects on composite endpoints are primarily driven by a reduction in non-fatal stroke [123]. The cardiovascular safety of liraglutide was investigated in the LEADER trial, which enrolled patients who had T2DM and $81.3 \%$ had established cardiovascular disease. The rate of the first occurrence of the primary endpoint, which included non-fatal MI, non-fatal stroke, cardiovascular disease, and all-cause mortality, was significantly reduced with liraglutide (HR, 0.87; 95\% CI, 0.78-0.97). It did not cause a significant reduction in the rates of HF hospitalization, nonfatal MI, and non-fatal stroke compared to the placebo group [124]. Due to the positive results from SUSTAIN-6 and LEADER, GLP-1 receptor agonists may still ultimately improve T2DM patient's CV outcomes. However, it seems that neither HF events nor HF hospitalization are affected by GLP1 receptor agonists. The EXSCEL trial was another CV outcome trial that randomized 14,752 patients to either exenatide (2 mg once weekly) or placebo. The primary composite endpoint of CV death, non-fatal MI, and non-fatal stroke did not differ between exenatide and placebo (HR, 0.91; 95\%CI, 0.83-1.00). There was also no difference in fatal or non-fatal MI and stroke, and hospitalization for HF and ACS [125].

The effects of liraglutide on clinical stability following hospitalization for acute HF was studied in a phase 2, doubleblind, placebo-controlled trial (FIGHT trial). There was no difference in the rate of deaths (HR, 1.10; 95\% CI, $0.57-$ 2.14) or rehospitalizations for $\mathrm{HF}$ (HR, 1.30; 95\% CI, 0.89 1.88 ) between liraglutide and placebo [126].

\section{Conclusion and Take Home Message}

DM and HF are global epidemics, representing a major burden on the global health care system. A significant body of evidence indicates that the conditions are closely intertwined. HF therapies currently available have a similar degree of effectiveness in patients with and without T2DM. Tight glycemic control does not improve HF outcomes, but the choice of glucose-lowering agent can substantially affect HF-related outcome. For older glucose-lowering agents, such as insulin and sulfonylureas, there is insufficient evidence indicating the effects on HF outcomes in patients with diabetes and with established HF due to the lack of randomized controlled trials. TZDs are clearly associated with an increased risk of developing HF and worsening of pre-existing HF and should therefore be avoided in subjects at risk for HF. For saxagliptin (DDP-4 inhibitor), an increased risk for HF hospitalization has been reported. GLP-1RAs do not appear to increase the risk of developing HF, although there is uncertainty about the effects in patients with established HF. SGLT-2 inhibitors have been found to reduce the HF hospitalization in T2DM, and 


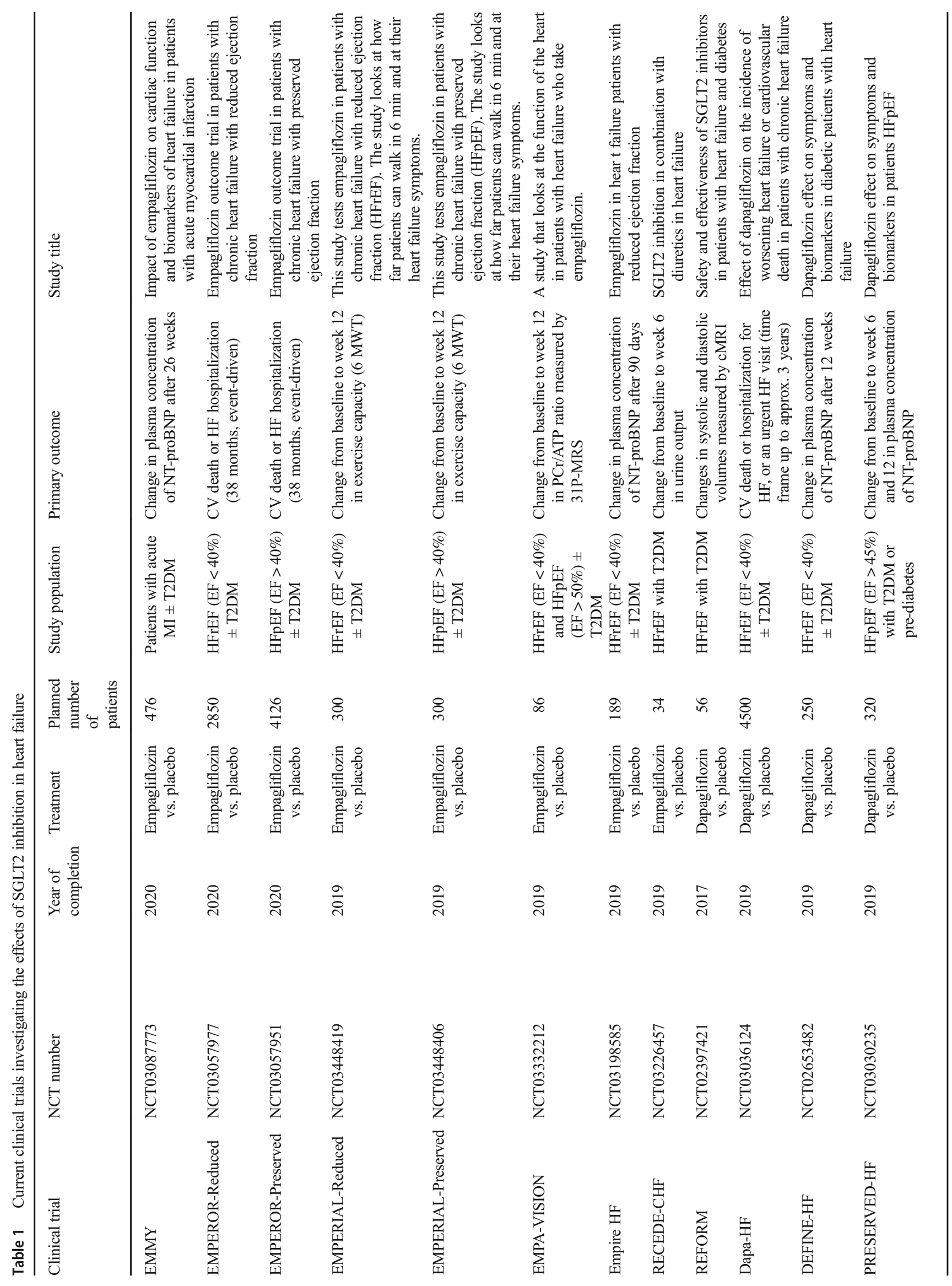




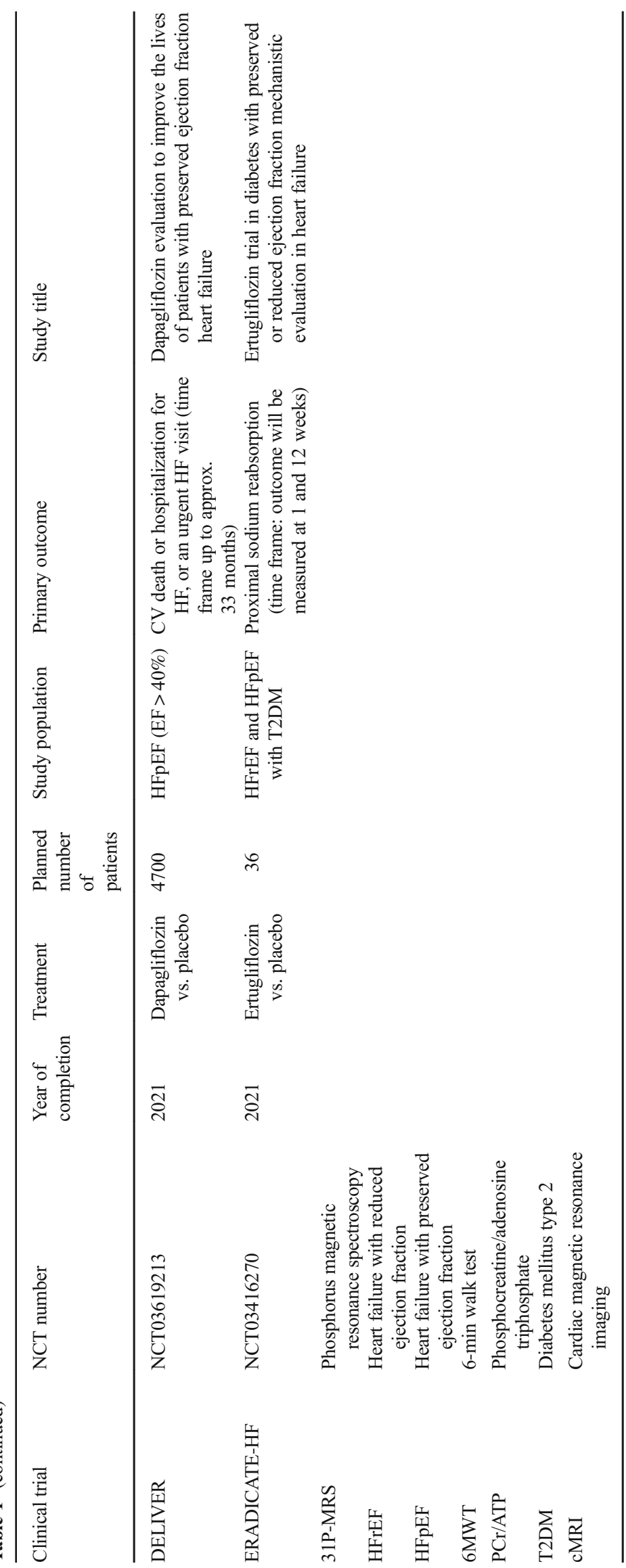


their safety and efficacy were confirmed in patients with diabetes with established HF. Although recent clinical trials have provided more insights regarding the efficacy and safety of glucose-lowering drugs, the available data is still insufficient for making firm evidence-based recommendations about optimal treatment of patients with diabetes and HF.

Funding Information Open access funding provided by Medical University of Graz.

\section{Compliance with Ethical Standards}

Conflict of Interest Markus Wallner and Deborah M. Eaton declare that they have no conflict of interest. Harald Sourij reports grants, personal fees, and other from Astra Zeneca, Böhringer Ingelheim, MSD, Novo Nordisk, Eli Lilly, and Sanofi. Dirk von Lewinski reports grants from Boehringer, and personal fees from AstraZeneca and Novo Nordisk.

Human and Animal Rights and Informed Consent This article does not contain any studies with human or animal subjects performed by any of the authors.

Open Access This article is distributed under the terms of the Creative Commons Attribution 4.0 International License (http:// creativecommons.org/licenses/by/4.0/), which permits unrestricted use, distribution, and reproduction in any medium, provided you give appropriate credit to the original author(s) and the source, provide a link to the Creative Commons license, and indicate if changes were made.

\section{References}

Papers of particular interest, published recently, have been highlighted as:

- Of importance

1. Shaw JE, Sicree RA, Zimmet PZ. Global estimates of the prevalence of diabetes for 2010 and 2030. Diabetes Res Clin Pract. 2010;87:4-14.

2. Organization WH. Global report on diabetes. 2016.

3. Kaplan A, Abidi E, El-Yazbi A, Eid A, Booz GW, Zouein FA. Direct cardiovascular impact of SGLT2 inhibitors: mechanisms and effects. Heart Fail Rev. 2018;23:419-37.

4. Kannel WB, Hjortland M, Castelli WP. Role of diabetes in congestive heart failure: the Framingham study. Am J Cardiol. 1974;34:29-34.

5. Schmidt M, Jacobsen JB, Lash TL, Botker HE, Sorensen HT. 25 year trends in first time hospitalisation for acute myocardial infarction, subsequent short and long term mortality, and the prognostic impact of sex and comorbidity: a Danish nationwide cohort study. BMJ. 2012;344:e356.

6. Investigators S, Yusuf S, Pitt B, Davis CE, Hood WB, Cohn JN. Effect of enalapril on survival in patients with reduced left ventricular ejection fractions and congestive heart failure. $\mathrm{N}$ Engl $\mathrm{J}$ Med. 1991;325:293-302.

7. Group CTS. Effects of enalapril on mortality in severe congestive heart failure. Results of the Cooperative North Scandinavian Enalapril Survival Study (CONSENSUS). N Engl J Med. 1987;316:1429-35.
8. Pitt B, Zannad F, Remme WJ, Cody R, Castaigne A, Perez A, et al. The effect of spironolactone on morbidity and mortality in patients with severe heart failure. Randomized Aldactone Evaluation Study Investigators. N Engl J Med. 1999;341:709-17.

9. Nichols GA, Gullion CM, Koro CE, Ephross SA, Brown JB. The incidence of congestive heart failure in type 2 diabetes: an update. Diabetes Care. 2004;27:1879-84.

10. Nichols GA, Hillier TA, Erbey JR, Brown JB. Congestive heart failure in type 2 diabetes: prevalence, incidence, and risk factors. Diabetes Care. 2001;24:1614-9.

11. Sarma S, Mentz RJ, Kwasny MJ, Fought AJ, Huffman M, Subacius $\mathrm{H}$, et al. Association between diabetes mellitus and post-discharge outcomes in patients hospitalized with heart failure: findings from the EVEREST trial. Eur J Heart Fail. 2013;15: 194-202.

12. Packer M. Activation and inhibition of sodium-hydrogen exchanger is a mechanism that links the pathophysiology and treatment of diabetes mellitus with that of heart failure. Circulation. 2017;136:1548-59.

13. Uriel N, Naka Y, Colombo PC, Farr M, Pak SW, Cotarlan V, et al. Improved diabetic control in advanced heart failure patients treated with left ventricular assist devices. Eur J Heart Fail. 2011;13: 195-9.

14. Guglin M, Villafranca A, Morrison A. Cardiogenic diabetes. Heart Fail Rev. 2014;19:595-602.

15. Berl T, Hunsicker LG, Lewis JB, Pfeffer MA, Porush JG, Rouleau JL, et al. Collaborative study G. Cardiovascular outcomes in the Irbesartan Diabetic Nephropathy Trial of patients with type 2 diabetes and overt nephropathy. Ann Intern Med. 2003;138:542-9.

16. Savarese G, Lund LH. Global public health burden of heart failure. Card Fail Rev. 2017;3:7-11.

17. De Groote P, Lamblin N, Mouquet F, Plichon D, McFadden E, Van Belle E, et al. Impact of diabetes mellitus on long-term survival in patients with congestive heart failure. Eur Heart J. 2004;25:656-62.

18. Bertoni AG, Hundley WG, Massing MW, Bonds DE, Burke GL, Goff DC Jr. Heart failure prevalence, incidence, and mortality in the elderly with diabetes. Diabetes Care. 2004;27:699-703.

19. Jorsal A, Wiggers H, McMurray JJV. Heart failure: epidemiology, pathophysiology, and management of heart failure in diabetes mellitus. Endocrinol Metab Clin N Am. 2018;47:117-35.

20. Ponikowski P, Voors AA, Anker SD, Bueno H, Cleland JG, Coats $\mathrm{AJ}$, et al. Authors/Task Force MESC guidelines for the diagnosis and treatment of acute and chronic heart failure: the task force for the diagnosis and treatment of acute and chronic heart failure of the European Society of Cardiology (ESC) developed with the special contribution of the Heart Failure Association (HFA) of the ESC. Eur Heart J. 2016;37:2129-200.

21. Yancy CW, Jessup M, Bozkurt B, Butler J, Casey DE Jr, Colvin MM, et al. 2017 ACC/AHA/HFSA focused update of the 2013 ACCF/AHA guideline for the management of heart failure: a report of the American College of Cardiology/American Heart Association Task Force on Clinical Practice Guidelines and the Heart Failure Society of America. Circulation. 2017;136:e137-61.

22. Duckworth W, Abraira C, Moritz T, Reda D, Emanuele N, Reaven $\mathrm{PD}$, et al. Glucose control and vascular complications in veterans with type 2 diabetes. N Engl J Med. 2009;360:129-39.

23. Group AS, Cushman WC, Evans GW, Byington RP, Goff DC Jr, Grimm RH Jr, et al. Effects of intensive blood-pressure control in type 2 diabetes mellitus. N Engl J Med. 2010;362:1575-85.

24. Patel A, MacMahon S, Chalmers J, Neal B, Billot L, Woodward $\mathrm{M}$, et al. Intensive blood glucose control and vascular outcomes in patients with type 2 diabetes. N Engl J Med. 2008;358:2560-72.

25. Stratton IM, Adler AI, Neil HA, Matthews DR, Manley SE, Cull $\mathrm{CA}$, et al. Association of glycaemia with macrovascular and 
microvascular complications of type 2 diabetes (UKPDS 35): prospective observational study. BMJ. 2000;321:405-12.

26. Selvin E, Lazo M, Chen Y, Shen L, Rubin J, McEvoy JW, et al. Diabetes mellitus, prediabetes, and incidence of subclinical myocardial damage. Circulation. 2014;130:1374-82.

27. Rawshani A, Rawshani A, Franzen S, Sattar N, Eliasson B, Svensson AM, et al. Risk factors, mortality, and cardiovascular outcomes in patients with type 2 diabetes. N Engl J Med. 2018;379:633-44.

28. Eshaghian S, Horwich TB, Fonarow GC. An unexpected inverse relationship between $\mathrm{HbAlc}$ levels and mortality in patients with diabetes and advanced systolic heart failure. Am Heart J. 2006;151:91.

29. Hussain Z, Arooj M, Malik A, Hussain F, Safdar H, Khan S, et al. Nanomedicines as emerging platform for simultaneous delivery of cancer therapeutics: new developments in overcoming drug resistance and optimizing anticancer efficacy. Artif Cells Nanomed Biotechnol. 2018;6:1-10.

30. McMurray JJ, Gerstein HC, Holman RR, Pfeffer MA. Heart failure: a cardiovascular outcome in diabetes that can no longer be ignored. Lancet Diabetes Endocrinol. 2014;2:843-51.

31. Fitchett DH, Udell JA, Inzucchi SE. Heart failure outcomes in clinical trials of glucose-lowering agents in patients with diabetes. Eur J Heart Fail. 2017;19:43-53.

32. Ryden L, Grant PJ, Anker SD, Berne C, Cosentino F, Danchin N, et al. ESC guidelines on diabetes, pre-diabetes, and cardiovascular diseases developed in collaboration with the EASD: the task force on diabetes, pre-diabetes, and cardiovascular diseases of the European Society of Cardiology (ESC) and developed in collaboration with the European Association for the Study of Diabetes (EASD). Eur Heart J. 2013;34:3035-87.

33. Jia G, DeMarco VG, Sowers JR. Insulin resistance and hyperinsulinaemia in diabetic cardiomyopathy. Nat Rev Endocrinol. 2016;12:144-53.

34. von Lewinski D, Kolesnik E, Wallner M, Resl M, Sourij H. New antihyperglycemic drugs and heart failure: synopsis of basic and clinical data. Biomed Res Int. 2017;2017:1253425.

35. Regan TJ, Lyons MM, Ahmed SS, Levinson GE, Oldewurtel HA, Ahmad MR, et al. Evidence for cardiomyopathy in familial diabetes mellitus. J Clin Invest. 1977;60:884-99.

36. Kasznicki J, Drzewoski J. Heart failure in the diabetic population pathophysiology, diagnosis and management. Arch Med Sci. 2014;10:546-56.

37. Aronson D. Cross-linking of glycated collagen in the pathogenesis of arterial and myocardial stiffening of aging and diabetes. $\mathrm{J}$ Hypertens. 2003;21:3-12.

38. Poornima IG, Parikh P, Shannon RP. Diabetic cardiomyopathy: the search for a unifying hypothesis. Circ Res. 2006;98:596-605.

39. Lehrke M, Marx N. Diabetes mellitus and heart failure. Am J Cardiol. 2017;120:S37-47.

40. Nishikawa T, Araki E. Impact of mitochondrial ROS production in the pathogenesis of diabetes mellitus and its complications. Antioxid Redox Signal. 2007;9:343-53.

41. Jia G, Hill MA, Sowers JR. Diabetic cardiomyopathy: an update of mechanisms contributing to this clinical entity. Circ Res. 2018;122:624-38.

42. Stentz FB, Umpierrez GE, Cuervo R, Kitabchi AE. Proinflammatory cytokines, markers of cardiovascular risks, oxidative stress, and lipid peroxidation in patients with hyperglycemic crises. Diabetes. 2004;53:2079-86.

43. Goldin A, Beckman JA, Schmidt AM, Creager MA. Advanced glycation end products: sparking the development of diabetic vascular injury. Circulation. 2006;114:597-605.

44. Parhofer KG. Interaction between glucose and lipid metabolism: more than diabetic dyslipidemia. Diabetes Metab J. 2015;39:35362.
45. Verges B. Pathophysiology of diabetic dyslipidaemia: where are we? Diabetologia. 2015;58:886-99.

46. Dunmore SJ, Brown JE. The role of adipokines in beta-cell failure of type 2 diabetes. J Endocrinol. 2013;216:T37-45.

47. von Lewinski D, Gasser R, Rainer PP, Huber MS, Wilhelm B, Roessl U, et al. Functional effects of glucose transporters in human ventricular myocardium. Eur J Heart Fail. 2010;12:106-13.

48. Belke DD, Dillmann WH. Altered cardiac calcium handling in diabetes. Curr Hypertens Rep. 2004;6:424-9.

49. Hermann HP, Pieske B, Schwarzmuller E, Keul J, Just H, Hasenfuss G. Haemodynamic effects of intracoronary pyruvate in patients with congestive heart failure: an open study. Lancet. 1999;353:1321-3.

50. Hasenfuss G, Maier LS, Hermann HP, Luers C, Hunlich M, Zeitz $\mathrm{O}$, et al. Influence of pyruvate on contractile performance and $\mathrm{Ca}(2+)$ cycling in isolated failing human myocardium. Circulation. 2002;105:194-9.

51. Rijzewijk LJ, Jonker JT, van der Meer RW, Lubberink M, de Jong HW, Romijn JA, et al. Effects of hepatic triglyceride content on myocardial metabolism in type 2 diabetes. J Am Coll Cardiol. 2010;56:225-33.

52. Neubauer S. The failing heart-an engine out of fuel. N Engl J Med. 2007;356:1140-51.

53. Doehner W, Rauchhaus M, Ponikowski P, Godsland IF, von Haehling S, Okonko DO, et al. Impaired insulin sensitivity as an independent risk factor for mortality in patients with stable chronic heart failure. J Am Coll Cardiol. 2005;46:1019-26.

54. Brands MW, Manhiani MM. Sodium-retaining effect of insulin in diabetes. Am J Physiol Regul Integr Comp Physiol. 2012;303: R1101-9.

55. Riehle C, Abel ED. Insulin signaling and heart failure. Circ Res. 2016;118:1151-69.

56. Packer M. Potentiation of insulin signaling contributes to heart failure in type 2 diabetes: a hypothesis supported by both mechanistic studies and clinical trials. JACC Basic Transl Sci. 2018;3: 415-9.

57. Li Q, Park K, Li C, Rask-Madsen C, Mima A, Qi W, et al. Induction of vascular insulin resistance and endothelin-1 expression and acceleration of atherosclerosis by the overexpression of protein kinase C-beta isoform in the endothelium. Circ Res. 2013;113:418-27.

58. Manhiani MM, Cormican MT, Brands MW. Chronic sodiumretaining action of insulin in diabetic dogs. Am J Physiol Renal Physiol. 2011;300:F957-65.

59. Rocchini AP, Katch V, Kveselis D, Moorehead C, Martin M, Lampman R, et al. Insulin and renal sodium retention in obese adolescents. Hypertension. 1989;14:367-74.

60. Pocock SJ, Wang D, Pfeffer MA, Yusuf S, McMurray JJ, Swedberg KB, et al. Predictors of mortality and morbidity in patients with chronic heart failure. Eur Heart J. 2006;27:65-75.

61. Domanski M, Krause-Steinrauf H, Deedwania P, Follmann D, Ghali JK, Gilbert E, et al. The effect of diabetes on outcomes of patients with advanced heart failure in the BEST trial. J Am Coll Cardiol. 2003;42:914-22.

62. Smooke S, Horwich TB, Fonarow GC. Insulin-treated diabetes is associated with a marked increase in mortality in patients with advanced heart failure. Am Heart J. 2005;149:168-74.

63. Gerstein HC, Bosch J, Dagenais GR, Diaz R, Jung H, Maggioni AP, et al. Basal insulin and cardiovascular and other outcomes in dysglycemia. N Engl J Med. 2012;367:319-28.

64. Nielsen R, Wiggers H, Thomsen HH, Bovin A, Refsgaard J, Abrahamsen J, et al. Effect of tighter glycemic control on cardiac function, exercise capacity, and muscle strength in heart failure patients with type 2 diabetes: a randomized study. BMJ Open Diabetes Res Care. 2016;4:e00202. 
65. Eurich DT, Majumdar SR, McAlister FA, Tsuyuki RT, Johnson JA. Improved clinical outcomes associated with metformin in patients with diabetes and heart failure. Diabetes Care. 2005;28: 2345-51.

66. Pantalone KM, Kattan MW, Yu C, Wells BJ, Arrigain S, Jain A, et al. The risk of developing coronary artery disease or congestive heart failure, and overall mortality, in type 2 diabetic patients receiving rosiglitazone, pioglitazone, metformin, or sulfonylureas: a retrospective analysis. Acta Diabetol. 2009;46:145-54.

67. Andersson C, Olesen JB, Hansen PR, Weeke P, Norgaard ML, Jorgensen $\mathrm{CH}$, et al. Metformin treatment is associated with a low risk of mortality in diabetic patients with heart failure: a retrospective nationwide cohort study. Diabetologia. 2010;53:254653.

68. Masoudi FA, Inzucchi SE, Wang Y, Havranek EP, Foody JM, Krumholz HM. Thiazolidinediones, metformin, and outcomes in older patients with diabetes and heart failure: an observational study. Circulation. 2005;111:583-90.

69. Group UPDSU. Effect of intensive blood-glucose control with metformin on complications in overweight patients with type 2 diabetes (UKPDS 34). Lancet. 1998;352:854-65.

70. Dormandy JA, Charbonnel B, Eckland DJ, Erdmann E, MassiBenedetti M, Moules IK, et al. Secondary prevention of macrovascular events in patients with type 2 diabetes in the PROactive study (PROspective pioglitAzone Clinical Trial in macroVascular Events): a randomised controlled trial. Lancet. 2005;366:1279-89.

71. Vaccaro O, Masulli M, Nicolucci A, Bonora E, Del Prato S, Maggioni AP, et al. Effects on the incidence of cardiovascular events of the addition of pioglitazone versus sulfonylureas in patients with type 2 diabetes inadequately controlled with metformin (TOSCA.IT): a randomised, multicentre trial. Lancet Diabetes Endocrinol. 2017;5:887-97.

72. Gerstein HC, Yusuf S, Bosch J, Pogue J, Sheridan P, Dinccag N, et al. Effect of rosiglitazone on the frequency of diabetes in patients with impaired glucose tolerance or impaired fasting glucose: a randomised controlled trial. Lancet. 2006;368:1096-105.

73. Home PD, Pocock SJ, Beck-Nielsen H, Curtis PS, Gomis R, Hanefeld M, et al. Rosiglitazone evaluated for cardiovascular outcomes in oral agent combination therapy for type 2 diabetes (RECORD): a multicentre, randomised, open-label trial. Lancet. 2009;373:2125-35.

74. Giles TD, Elkayam U, Bhattacharya M, Perez A, Miller AB. Comparison of pioglitazone vs glyburide in early heart failure: insights from a randomized controlled study of patients with type 2 diabetes and mild cardiac disease. Congest Heart Fail. 2010;16: $111-7$.

75. Dargie HJ, Hildebrandt PR, Riegger GA, McMurray JJ, McMorn SO, Roberts JN, et al. A randomized, placebo-controlled trial assessing the effects of rosiglitazone on echocardiographic function and cardiac status in type 2 diabetic patients with New York Heart Association functional class I or II heart failure. J Am Coll Cardiol. 2007;49:1696-704.

76. Holman RR, Paul SK, Bethel MA, Matthews DR, Neil HA. 10year follow-up of intensive glucose control in type 2 diabetes. N Engl J Med. 2008;359:1577-89.

77. Wong AK, Symon R, AlZadjali MA, Ang DS, Ogston S, Choy A, et al. The effect of metformin on insulin resistance and exercise parameters in patients with heart failure. Eur J Heart Fail. 2012;14: 1303-10.

78. Aguilar D, Chan W, Bozkurt B, Ramasubbu K, Deswal A. Metformin use and mortality in ambulatory patients with diabetes and heart failure. Circ Heart Fail. 2011;4:53-8.

79. Evans JM, Doney AS, AlZadjali MA, Ogston SA, Petrie JR, Morris AD, et al. Effect of metformin on mortality in patients with heart failure and type 2 diabetes mellitus. Am J Cardiol. 2010;106: 1006-10.

80. MacDonald MR, Eurich DT, Majumdar SR, Lewsey JD, Bhagra S, Jhund PS, et al. Treatment of type 2 diabetes and outcomes in patients with heart failure: a nested case-control study from the U.K. general practice research database. Diabetes Care. 2010;33: 1213-8.

81. MacDonald MR, Petrie MC, Hawkins NM, Petrie JR, Fisher M, McKelvie R, et al. Diabetes, left ventricular systolic dysfunction, and chronic heart failure. Eur Heart J. 2008;29:1224-40.

82. Weir DL, Abrahamowicz M, Beauchamp ME, Eurich DT. Acute vs cumulative benefits of metformin use in patients with type 2 diabetes and heart failure. Diabetes Obes Metab. 2018.

83. dos Santos L, Salles TA, Arruda-Junior DF, Campos LC, Pereira AC, Barreto AL, et al. Circulating dipeptidyl peptidase IV activity correlates with cardiac dysfunction in human and experimental heart failure. Circ Heart Fail. 2013;6:1029-38.

84. Mulvihill EE, Drucker DJ. Pharmacology, physiology, and mechanisms of action of dipeptidyl peptidase-4 inhibitors. Endocr Rev. 2014;35:992-1019.

85. Luconi M, Cantini G, Ceriello A, Mannucci E. Perspectives on cardiovascular effects of incretin-based drugs: from bedside to bench, return trip. Int J Cardiol. 2017;241:302-10.

86. Shigeta T, Aoyama M, Bando YK, Monji A, Mitsui T, Takatsu M, et al. Dipeptidyl peptidase-4 modulates left ventricular dysfunction in chronic heart failure via angiogenesis-dependent and independent actions. Circulation. 2012;126:1838-51.

87. Takahashi A, Asakura M, Ito S, Min KD, Shindo K, Yan Y, et al. Dipeptidyl-peptidase IV inhibition improves pathophysiology of heart failure and increases survival rate in pressure-overloaded mice. Am J Physiol Heart Circ Physiol. 2013;304:H1361-9.

88. Kim NH, Yu T, Lee DH. The nonglycemic actions of dipeptidyl peptidase-4 inhibitors. Biomed Res Int. 2014;2014:368703.

89. Zhong J, Maiseyeu A, Davis SN, Rajagopalan S. DPP4 in cardiometabolic disease: recent insights from the laboratory and clinical trials of DPP4 inhibition. Circ Res. 2015;116:1491-504.

90. Balakumar P, Dhanaraj SA. Cardiovascular pleiotropic actions of DPP-4 inhibitors: a step at the cutting edge in understanding their additional therapeutic potentials. Cell Signal. 2013;25:1799-803.

91. Scirica BM, Bhatt DL, Braunwald E, Steg PG, Davidson J, Hirshberg B, et al. Saxagliptin and cardiovascular outcomes in patients with type 2 diabetes mellitus. N Engl J Med. 2013;369: 1317-26.

92. White WB, Cannon CP, Heller SR, Nissen SE, Bergenstal RM, Bakris GL, et al. Alogliptin after acute coronary syndrome in patients with type 2 diabetes. N Engl J Med. 2013;369:1327-35.

93. Green JB, Bethel MA, Armstrong PW, Buse JB, Engel SS, Garg J, et al. Effect of sitagliptin on cardiovascular outcomes in type 2 diabetes. N Engl J Med. 2015;373:232-42.

94. Koyani CN, Kolesnik E, Wolkart G, Shrestha N, Scheruebel S, Trummer C, et al. Dipeptidyl peptidase-4 independent cardiac dysfunction links saxagliptin to heart failure. Biochem Pharmacol. 2017;145:64-80.

95. Zinman B, Wanner C, Lachin JM, Fitchett D, Bluhmki E, Hantel $\mathrm{S}$, et al. Empagliflozin, cardiovascular outcomes, and mortality in type 2 diabetes. N Engl J Med. 2015;373:2117-28. The EMPAREG outcome trial demonstrated a significant reduction in the primary MACE endpoint, as well as cardiovascular and all-cause mortality and hospitalization for heart failure in the empagliflozin-treated arm.

96. Neal B, Perkovic V, Mahaffey KW, Fulcher G, Erondu N, Desai $\mathrm{M}$, et al. Optimizing the analysis strategy for the CANVAS Program: A prespecified plan for the integrated analyses of the CANVAS and CANVAS-R trials. Diabetes Obes Metab. 2017;19:926-35. 
97. Neal B, Perkovic V, Mahaffey KW, de Zeeuw D, Fulcher G, Erondu N, et al. Canagliflozin and cardiovascular and renal events in type 2 diabetes. N Engl J Med. 2017;377:644-57. The CANVAS program demonstrated a reduction of MACE events and hospitalization for heart failure in the canagliflozin-treated arm.

98. Habibi J, Aroor AR, Sowers JR, Jia G, Hayden MR, Garro M, et al. Sodium glucose transporter 2 (SGLT2) inhibition with empagliflozin improves cardiac diastolic function in a female rodent model of diabetes. Cardiovasc Diabetol. 2017;16:9.

99. Hammoudi N, Jeong D, Singh R, Farhat A, Komajda M, Mayoux E, et al. Empagliflozin improves left ventricular diastolic dysfunction in a genetic model of type 2 diabetes. Cardiovasc Drugs Ther. 2017;31:233-46.

100. Ferrannini E, Mark M, Mayoux E. CV protection in the EMPAREG OUTCOME trial: a "thrifty substrate" hypothesis. Diabetes Care. 2016;39:1108-14

101. Bonner C, Kerr-Conte J, Gmyr V, Queniat G, Moerman E, Thevenet J, et al. Inhibition of the glucose transporter SGLT2 with dapagliflozin in pancreatic alpha cells triggers glucagon secretion. Nat Med. 2015;21:512-7.

102. Al Jobori H, Daniele G, Adams J, Cersosimo E, Triplitt C, DeFronzo RA, et al. Determinants of the increase in ketone concentration during SGLT2 inhibition in NGT, IFG and T2DM patients. Diabetes Obes Metab. 2017;19:809-13.

103. Ussher JR, Elmariah S, Gerszten RE, Dyck JR. The emerging role of metabolomics in the diagnosis and prognosis of cardiovascular disease. J Am Coll Cardiol. 2016;68:2850-70.

104. Baartscheer A, Schumacher CA, Wust RC, Fiolet JW, Stienen GJ, Coronel R, et al. Empagliflozin decreases myocardial cytoplasmic $\mathrm{Na}(+)$ through inhibition of the cardiac $\mathrm{Na}(+) / \mathrm{H}(+)$ exchanger in rats and rabbits. Diabetologia. 2017;60:568-73.

105. Heerspink HJ, Perkins BA, Fitchett DH, Husain M, Cherney DZ. Sodium glucose cotransporter 2 inhibitors in the treatment of diabetes mellitus: cardiovascular and kidney effects, potential mechanisms, and clinical applications. Circulation. 2016;134:752-72.

106. Marx N, McGuire DK. Sodium-glucose cotransporter-2 inhibition for the reduction of cardiovascular events in high-risk patients with diabetes mellitus. Eur Heart J. 2016;37:3192-200.

107. Chilton R, Tikkanen I, Cannon CP, Crowe S, Woerle HJ, Broedl $\mathrm{UC}$, et al. Effects of empagliflozin on blood pressure and markers of arterial stiffness and vascular resistance in patients with type 2 diabetes. Diabetes Obes Metab. 2015;17:1180-93.

108. Sano M, Takei M, Shiraishi Y, Suzuki Y. Increased hematocrit during sodium-glucose cotransporter 2 inhibitor therapy indicates recovery of tubulointerstitial function in diabetic kidneys. J Clin Med Res. 2016;8:844-7.

109. Butler J, Hamo CE, Filippatos G, Pocock SJ, Bernstein RA, Brueckmann $\mathrm{M}$, et al. The potential role and rationale for treatment of heart failure with sodium-glucose co-transporter 2 inhibitors. Eur J Heart Fail. 2017;19:1390-400.

110. Mojsov S, Heinrich G, Wilson IB, Ravazzola M, Orci L, Habener JF. Preproglucagon gene expression in pancreas and intestine diversifies at the level of post-translational processing. J Biol Chem. 1986;261:11880-9.

111. Kieffer TJ, McIntosh CH, Pederson RA. Degradation of glucosedependent insulinotropic polypeptide and truncated glucagon-like peptide 1 in vitro and in vivo by dipeptidyl peptidase IV. Endocrinology. 1995;136:3585-96.

112. Serre V, Dolci W, Schaerer E, Scrocchi L, Drucker D, Efrat S, et al. Exendin-(9-39) is an inverse agonist of the murine glucagon-like peptide-1 receptor: implications for basal intracellular cyclic adenosine $3{ }^{\prime}, 5^{\prime}$-monophosphate levels and beta-cell glucose competence. Endocrinology. 1998;139:4448-54.

113. Meier JJ. GLP-1 receptor agonists for individualized treatment of type 2 diabetes mellitus. Nat Rev Endocrinol. 2012;8:728-42.

114. Drucker DJ, Nauck MA. The incretin system: glucagon-like peptide-1 receptor agonists and dipeptidyl peptidase- 4 inhibitors in type 2 diabetes. Lancet. 2006;368:1696-705.

115. Nikolaidis LA, Mankad S, Sokos GG, Miske G, Shah A, Elahi D, et al. Effects of glucagon-like peptide-1 in patients with acute myocardial infarction and left ventricular dysfunction after successful reperfusion. Circulation. 2004;109:962-5.

116. Koska J, Schwartz EA, Mullin MP, Schwenke DC, Reaven PD. Improvement of postprandial endothelial function after a single dose of exenatide in individuals with impaired glucose tolerance and recent-onset type 2 diabetes. Diabetes Care. 2010;33:102830.

117. Lonborg J, Vejlstrup N, Kelbaek H, Botker HE, Kim WY, Mathiasen $\mathrm{AB}$, et al. Exenatide reduces reperfusion injury in patients with ST-segment elevation myocardial infarction. Eur Heart J. 2012;33:1491-9.

118. Kim M, Platt MJ, Shibasaki T, Quaggin SE, Backx PH, Seino S, et al. GLP-1 receptor activation and Epac2 link atrial natriuretic peptide secretion to control of blood pressure. Nat Med. 2013;19: 567-75.

119. Richards P, Parker HE, Adriaenssens AE, Hodgson JM, Cork SC, Trapp S, et al. Identification and characterization of GLP-1 receptor-expressing cells using a new transgenic mouse model. Diabetes. 2014;63:1224-33.

120. Wohlfart P, Linz W, Hubschle T, Linz D, Huber J, Hess S, et al. Cardioprotective effects of lixisenatide in rat myocardial ischemiareperfusion injury studies. J Transl Med. 2013;11:84.

121. Wallner M, Kolesnik E, Ablasser K, Khafaga M, Wakula P, Ljubojevic S, et al. Exenatide exerts a PKA-dependent positive inotropic effect in human atrial myocardium: GLP-1R mediated effects in human myocardium. J Mol Cell Cardiol. 2015;89:36575.

122. Pfeffer MA, Claggett B, Diaz R, Dickstein K, Gerstein HC, Kober $\mathrm{LV}$, et al. Lixisenatide in patients with type 2 diabetes and acute coronary syndrome. N Engl J Med. 2015;373:2247-57.

123. Marso SP, Bain SC, Consoli A, Eliaschewitz FG, Jodar E, Leiter LA, et al. Semaglutide and cardiovascular outcomes in patients with type 2 diabetes. N Engl J Med. 2016;375:1834 44.

124. Marso SP, Daniels GH, Brown-Frandsen K, Kristensen P, Mann JF, Nauck MA, et al. Liraglutide and cardiovascular outcomes in type 2 diabetes. N Engl J Med. 2016;375:311-22.

125. Holman RR, Bethel MA, Mentz RJ, Thompson VP, Lokhnygina Y, Buse JB, et al. Effects of once-weekly exenatide on cardiovascular outcomes in type 2 diabetes. N Engl J Med. 2017;377:122839.

126. Margulies KB, Hernandez AF, Redfield MM, Givertz MM, Oliveira GH, Cole R, et al. Effects of liraglutide on clinical stability among patients with advanced heart failure and reduced ejection fraction: a randomized clinical trial. JAMA. 2016;316:500-8. 